\title{
LOS CHOLOS \\ Y LA BUSQUEDA DE UNA NUEVA SOCIEDAD
}

POR

\author{
SUSAN TRITTEN
}

Wright State University

Tres novelas escritas por Carlos Medinaceli, Antonio Díaz Villamil y Víctor Hugo Villegas se dedican otra vez a un tema que ha preocupado tanto a escritores bolivianos: las cualidades de grupos étnicos y las relaciones raciales. Esta vez las tres narraciones tratan el tema del papel del cholo en establecer una sociedad netamente boliviana. Aunque La Chaska$\tilde{n} a w i$, de Carlos Medinaceli, parece haber sido empezada en los años veinte, las tres novelas que aquí estudiamos, incluyendo La niña de sus ojos, de Antonio Díaz Villamil, y Chuño Palma, novela de cholos, de Víctor Hugo Villegas, se publicaron en 1947 o 1948, durante la crisis intelectual y social ocasionada por la guerra del Chaco ${ }^{2}$. La literatura del período entre aquella guerra y la revolución de 1952 refleja y enfoca las inquietudes de los participantes en la guerra (las clases medias y bajas que se habían despertado a las injusticias sociales del sistema tradicional) ${ }^{3}$. Rechazando los valores europeos de los blancos, empezaron a buscar valores nacionales y a reivindicar a los mestizos. Estas tres novelas se parecen mucho, si no en estilo, en su investigación del carácter del cholo, o la chola, y en su aporte a la creación de una vida y valores auténticamente bolivianos. Por eso en esta nota breve voy a enfocar dos temas relacionados: el primero, el ca-

${ }^{1}$ Quisiera agradecerle al Centro de Estudios Latinoamericanos de la Universidad de Pittsburgh por un Summer Research Grant que me permitió hacer la investigación para este artículo.

${ }^{2}$ Las tres novelas comentadas en este estudio son: Carlos Medinaceli, La Chaskañawi (La Paz: Fundación Universitaria «Simón L. Patiño», 1947); Antonio Díaz Villamil, La niña de sus ojos (La Paz: Librería Editorial Juventud, 1956), y Víctor Hugo Villegas, Chuño Palma, novela de cholos (La Paz: 1948). Todas las citas se refieren a estas ediciones.

${ }^{3}$ Entre otras obras, véase Herbert Klein en Bolivia, The Evolution of a MultiEthnic Society (Nueva York \& Oxford: The Oxford University Press, 1982), p. 186. 
rácter de la chola como personaje importante, si no siempre principal, y el uso de este personaje como representante de un grupo emergente que lucha para establecerse en la sociedad, y el segundo, el proceso de transformación del héroe desde una posición de adhesión a falsos valores hacia una aceptación de la autenticidad de una vida que integra elementos de su herencia indígena con la europea y la necesidad de defender esa vida contra las fuerzas sociales y políticas.

En cada una de las tres novelas hay un personaje que actúa recíprocamente con el protagonista, pero que también representa un retrato verosímil de las cualidades morales y los problemas psicológicos con los que se enfrentan los cholos. Las tres son mujeres y en cada una se destaca una fuerza vital y una superioridad que se impone a todas las desgracias, frustraciones y prejuicios del vivir en un rango inferior. Es la misma fuerza que apoya y mantiene los valores netamente bolivianos y que conduce a los protagonistas (al hijo, a la hija o al amante) a una vida más útil, consciente de su debida contribución a la sociedad de su patria.

En todas las mujeres hay cualidades comunes que funcionan para definir la chola típica de la literatura. Los autores se empeñan en la mezcla de herencia racial en cada una de estas mujeres y así se distingue claramente la novela del cholo de la novela indigenista y su propósito de reivindicar ese grupo étnico. En cada descripción se destacan rasgos blancos tanto como indígenas. Típica de las descripciones es ésta de Doña Saturnina, la madre de Domy, protagonista de La niña de sus ojos: "Algo que la destacaba entre las cholas "recoveras" era el color blanco y sonrosado de su cutis, resultado indudable de un mestizaje que llegó a mostrar en ella cierta preponderancia de raza blanca. Solamente los pómulos prominentes, que acusaban su relieve aun sobre sus carrillos mofletudos, denotaban su parte de ascendencia indígena» ( $\mathrm{pp}, 9-10$ ). Y Claudina, la encantadora Chaskañawi, se parece a su tía Virginia, de la aristocracia fundadora de un pueblo provincial: "Tenía la misma graciosa prestancia, ese donaire de aquellas mujeres de la colonia, que aliaban lo señorial del linaje con la gracia de lo criollo» (p. 205). En ésta se destaca también la belleza de la mujer: «En lo que más se le parecía a su tía era en el óvalo casi perfecto de la cara y en la expresión vivaz, a ratos melancólica, de sus ojos. Ojos negros, almendrados, de un vivo escintilar de estrella, de rizadas pestañas, bajo el fino arco de las cejas. Lo que le valió, desde pequeña, el mote de "Chaskañawi"» (p. 205). La misma apariencia atractiva de la chola y de su ropa típica se repite en la descripción de Trini, la madre de Chuño Palma, cuando se viste para una conferencia con el director de la escuela de su hijo: 
Las botas de caña alta, íntegras de tacón por el uso moderado, torneaban bien las pantorrillas enfundadas en medias de muselina y regalaban a la poseedora aquella garrida prestancia de las cholas bien ataviadas, que salerosas, contoneantes y más altas de lo que en realidad son, suelen pasear por las calles en cualquier día de regocijo popular (pp. 71-72).

Paralelo al esfuerzo del autor para crear una mujer graciosa y demostrar la elegancia del atavío y de la persona misma de la chola, es su deseo de elogiar también la inteligencia, la listeza y la ambición de esa mujer ideal. Reflejando una realidad ya comentada en estudios históricos y etnológicos, las tres mujeres son comerciantes, pero comerciantes siempre exitosas. Trini y la Chaskañawi trabajan en sus propias tiendas de licores y restaurantes y Doña Saturnina vende comestibles en el mercado. Trini y Doña Saturnina son muy trabajadoras y ambiciosas. Esta descripción del éxito de Doña Saturnina destaca el respeto y la reputación que merecen las cholas dentro de su cultura:

Una de estas fruteras, la de más prestigio por la calidad de su fruta, y también por ello la que tiene más clientela, y está entre la gente de mayor calidad social y económica es doña Saturnina. Su puesto es el más surtido y el de mayor actividad (p. 9).

Las carreras de las dos madres cholas, Trini y Doña Saturnina, trazan un retrato bien conocido de la comerciante siempre dedicada al mejoramiento económico de su vida y muy ambiciosa para que se eduquen y sean aceptados sus hijos. Aunque la Chaskañawi, Claudina, también trabaja en la tienda de licores de su madre; como personaje principal, demuestra más la psicología, la angustia y las frustraciones de ser chola, inferior en la sociedad rígidamente estructurada de los Andes. Aunque tenía un padre de la aristocracia, su procedencia materna de una chola, Doña Pascuala García, la condena al rango de «pollera» (una mujer que usa las faldas del atavío de una chola). Siempre frustrada porque se siente superior a las senoritas decentes, pero desdeñada por ellas y por toda la clase alta, Claudina quiere probarse luchando por el amor de Adolfo, un hombre casado de la clase alta. A la vez ostenta su orgullo e independencia en no someterse a Adolfo y en desairar a los hombres de la clase alta que van con frecuencia a su tienda. A lo largo de la novela experimenta una variedad de emociones -el orgullo, el desdén, la crueldad-, todas como respuesta a su estado inescapable y su intento de ganar el amor de Adolfo.

\footnotetext{
${ }^{4}$ Véase Joseph M. Barnadas y Juan José Coy, Carlos Medinaceli: La Chaskañawi (Cochabamba: Editorial Los Amigos del Libros, 1977), p. 5.
} 
La cara y las formas bellas de las otras cholas que representan el valor de su raza también se notan en la figura de Claudina. Pero como sugiere su apodo, Chaskañawi (en quechua, ojos que brillan), sus ojos brillan además con un poder casi hechicero. Su poder de someter a su dominio a los hombres de cualquier clase, simbolizado por sus ojos refulgentes, significa la fuerza vital que le hace falta a la raza blanca, que está cayendo en la decadencia y en trabajos estériles. Un amigo de Adolfo la compara con Julia, su esposa blanca y débil:

Adolfo necesitaba una mujer así, que lo maneje y domine y tenga la fuerza que ella tiene para impedirle que se dé por completo a la bebida, como ya lo estaba haciendo cuando vivía con Julia, que era una mosca muerta, una «señorita mema», como el mismo Adolfo decía (p. 266).

Como en La Chaskañawi, en todas las tres novelas, las cualidades ideales de las tres mujeres ya descritas contribuyen a la creación de una mujer simbólica de una fuerza nacional y auténtica, que se arraiga no solamente en un pasado indígena, sino que también incluye la herencia europea. Es la fuerza eterna de la madre que engendra y nutre, pero expuesta en términos sociales y raciales, que sostendrá una sociedad nueva y que informará los ideales trascendentes y los destinos de los hijos de Doña Saturnina y de Trini y de Adolfo, el amante de Claudina. Las dos madres se dedican con una fuerza obsesiva a la educación y a la protección de sus hijos. Claudina no se dedica con menos fuerza a su lucha para crear una vida con Adolfo.

Es esta relación entre la chola de valores básicos y subyacentes y el hijo o amante que nos trae al segundo tema de este trabajo. Contra el trasfondo de valores eternos, los tres protagonistas pasan por el ciclo conocido del héroe contemporáneo, enajenado de su identidad verdadera, abismado entre valores falsos y, después de una crisis espiritual, restaurado a una identidad auténtica. En el caso de estas tres novelas bolivianas, aunque el ciclo se queda todavía fundido con lo psicológico, ha adquirido un significado social.

En todos los casos es la educación formal lo que enajena al protagonista, sea cholo o blanco. Todos los protagonistas son muy inteligentes, sobresalientes en su escuela, pero la educación les enseña los falsos valores, el comportamiento y los modales sólo de los blancos. Para hacerse conscientes de su estado alienado, cada uno de los tres pasa por una crisis distinta. Adolfo, el aristócrata, se da cuenta de su falta de voluntad, de sus borracheras frecuentes y del efecto debilitante de su educación, inapropiada, basada en la filosofía europea. Domy, la hermosa hija de Doña Satur- 
nina, con esperanzas de vivir en un ambiente elegante después de graduarse, se enferma al volver a la casa humilde de sus padres cholos. Para Chuño Palma, hijo de Trini, es la guerra del Chaco lo que despierta su voluntad. La fase final del ciclo, la vuelta, ofrece tres distintas variaciones de la posibilidad y la manera de establecer una sociedad que reconozca y reconcilie los elementos opuestos de la cultura boliviana.

Al final de La Chaskañawi, Adolfo, que ha rechazado la vida burguesa exigida por su mujer, Julia, goza de la vida del campo. En el epílogo, Adolfo charla con un viejo amigo de la universidad. El contraste con su vida anterior es notable. Adolfo, que se ve libre de las perversiones de la civilización hipócrita, describe su vida:

Por lo menos ahí vive uno lejos del mundanal ruido y franciscanamente fraternizando con la hermana agua, el hermano árbol, y también, ¿por qué no decirlo?, cuando llega la época de las brevas... el hermano vino a la sombra de los granados en flor. La vida es rústica, monótona, pero libre (p. 264).

En cambio, Fernando, su amigo, es un cajero de una compañía de minas. Su vida, dura y monótona, lo ha convertido en una cifra y se queja de su trabajo matador: «Pues, hombre... imuy bien!... En cambio, yo estoy a punto de embrutecerme, o de convertirme en una máquina de fabricar y hacer sumas» (p. 263). En la novela de Medinaceli, Adolfo relaciona a la chola maternal con la tierra para definir una realidad boliviana. El boliviano débil de procedencia europea necesitaba la vitalidad de la mujer chola para sobrevivir. Adolfo piensa en Claudina: «Era un fruto espontáneo de ese paisaje que da libre cauce a la corriente bullidora y gozosa, llena de alegría de la potencia creadora y se sentía rica, henchida de savia; su alma era maternal, no ascética» (p. 216).

En La niña de sus ojos, Domy es la bella mestiza que, después de formarse en la escuela de la aristocracia, decide ir de maestra a un pueblo indígena. Domy se convierte en el instrumento que va a forjar una nueva sociedad mestiza. Es la mezcla de influencia que se ve en Domy y en la ciudad, también mestiza, que superará la estratificación establecida y los antiguos prejuicios: «Con los ojos húmedos contempló aquella ciudad mestiza como ella, insatisfecha, dinámica y rebelde, empeñada también en imponer su destino sobre las adversidades y los odios...» (p. 214). El local de la vuelta de Domy también es el campo. Pero en vez de rechazar toda su educación y la civilización urbana, ella las utiliza para iluminar a los indígenas ignorantes. Pero Domy es siempre cuidadosa de no sencillamente imponer formas ajenas en una cultura establecida y valiosa. Guarda las 
tradiciones útiles de la cultura y crea una verdadera e íntegra mezcla apropiada a la gente, las costumbres y los recursos de la región:

Cada día buscaba nuevas formas y medios para afirmar y completar su plan de superación, pero, todo dentro de un límite razonable y real, tal como se lo señalaban la tierra, el clima, la tradición y la raza. Así, por ejemplo, no le pareció acertado alterar la vestimenta típica y sólo se esforzó en conseguir limpieza y decencia (p. 236).

Un éxito formidable recompensa los esfuerzos de Domy y allí también encuentra la paz de su alma.

Como presagio de la revolución de 1952, en Chuño Palma, novela de cholos no se expresa una solución tan fácil como en las dos novelas ya comentadas. En esta novela se plantea más bien un problema político. Chuño Palma, representante de los cholos, aunque bien educado, se une a un grupo de estudiantes idealistas que simpatizan con la clase obrera. En vez de una vuelta feliz del campo, Chuño es muerto en las barricadas durante una manifestación. El sacrificio de un cholo significa el principio de la lucha, y no el final exitoso, para superar barreras de clase tanto como de raza.

En estas tres novelas hemos visto la presencia de una chola, sea madre o amante, de cultura y procedencia mixta, que representa el origen que abriga y nutre una generación nueva. Esta generación, ya sea en sus logros o fracasos, pasa por una serie de peripecias que la llevan a una nueva comprensión del espíritu auténtico de Bolivia. En dos novelas, La Chaskañawi y La niña de sus ojos, el final sugiere que las generaciones futuras vivirán en un ambiente de paz e igualdad social. Domy y su amante criarán al hijo de él (que tiene una madre europea) en armonía social y en tranquilidad con los niños del pueblo indígena. Los hijos de Adolfo y la Chaskañawi también se formarán en la tranquilidad del campo. En cambio, en Chuño Palma..., la posibilidad de establecer una sociedad mestiza sólo llegará a ser una realidad después de una revolución. 